\title{
Análise dos acórdãos proferidos pelo TJDFT sobre medicamentos
}

\author{
Analysis of judgments delivered by TJDFT on unregistered medicines
}

Análisis de sentencias dictadas por TJDFT sobre los medicamentos no registrados en la ANVISA

RESUMO: O presente artigo tem como tema geral a análise sobre a concessão de medicamentos sem registro nacional, pelo TJDFT, nos anos 2013-2015. Apresenta, de forma sistematizada, os argumentos das decisões e a respectiva utilização dos fundamentos da suspensão de tutela antecipada (STA) 175 do Supremo Tribunal Federal (STF) e dos enunciados do Conselho Nacional de Justiça (CNJ), por qualquer das partes envolvidas no processo, a partir de descrição analítica dos dados qualiquantitativos. Apurou-se, dos acórdãos pesquisados, que os fundamentos da decisão STA 175 e dos enunciados serviram de fundamento para a concessão do medicamento sem registro nacional em benefício do usuário, mesmo não havendo comprovação nacional acerca de sua eficácia e segurança - o que ocorreu em $62 \%$ dos acórdãos estudados.

Palavras-chave: Direito à Saúde. Política de saúde. Comercialização de produtos. Vigilância Sanitária.

ABSTRACT: This article is general theme analysis on the provision of medicines no national registry at TJDFT in the years 2013-2015. Has so systematized the arguments of decisions and their use of the foundations of the preliminary injunction suspension (STA) 175 the Supreme Court (STF) and the utterances of the National Council of Justice (CNJ) by either party to the process, from analytical description of qualiquantitativos data. It was found of respondent's judgments, the grounds for the decision STA 175 and statements provided the basis for granting the medicine without national registry on behalf of the user, even without national evidence about their effectiveness and safety - which occurred in 62 $\%$ of the studied cases.

Keywords: Right to Health. Health Policy. Marketing of product. Sanitary Surveillance.

RESUMEN: Este artículo es el análisis de temática general en el suministro de medicamentos sin registro nacional TJDFT en los años 2013-2015. Ha de manera sistematizada los argumentos de las decisiones y el uso de las bases de la suspensión judicial preliminar (STA) 175 la Corte Suprema (STF) y las declaraciones del Consejo Nacional de Justicia (CNJ), por cualquiera de las partes en el proceso, de la descripción analítica de los datos cualitativos y cuantitativos. Se encontró de encuestados juicios, los

\footnotetext{
${ }^{1}$ Bacharel em Saúde Coletiva pela Universidade de Brasília (UnB-DF). Especializando em Direito Sanitário pela Fundação Osvaldo Cruz (Fiocruz- DF). Email: j.galvaomendes@gmail.com

${ }^{2}$ Doutoranda em Saúde Coletiva pela Universidade de Brasília (UnB). Advogada. Assessora Técnica do Conselho Nacional de Secretários de Saúde (Conass). Email: alethele@ig.com.br
} 
motivos de la decisión STA 175 y declaraciones servido de base para la concesión de la medicina sin registro nacional en nombre del usuario, incluso sin pruebas nacionales acerca de su efectividad y seguridad - que se produjo en el $62 \%$ de los casos estudiados.

Palabras-Ilave: Derecho a la Salud. La política de Salud. Comercialización de los productos. La vigilancia Sanitaria.

\section{Introdução}

Considerando o tema controverso, o presente artigo, sem a intenção de esgotar o assunto, apresenta os principais pontos do debate que envolve o fornecimento de medicamento sem registro nacional, pelo Estado Brasileiro, mediante determinação judicial, seus fundamentos legais e os acórdãos do Tribunal de Justiça do Distrito Federal e Territórios (TJDFT) nas ações judiciais julgadas nos anos 2013-2015, comparados à utilização dos argumentos apresentados pela decisão da Suspensão de Tutela Antecipada (STA) 175 e enunciados do Conselho Nacional de Justiça (CNJ).

No Brasil, os direitos sociais foram considerados fundamentais na Constituição Federal de 1988 (1) definidos em seu título II, que trata "Dos Direitos e Garantias Fundamentais" e os caracterizam como inegavelmente instrumentos de proteção e concretização do princípio da dignidade da pessoa humana (2).

A doutrina constitucional estabelece que as "normas definidoras de direitos fundamentais, mesmo os sociais, possuem uma força jurídica maximizada" (2). A afirmativa é ratificada por Barroso (3), para quem as normas não são apenas reconhecidas como documento jurídico, correspondendo unicamente ao exercício do Poder Legislativo e Executivo, o que leva a serem examinadas e aterem "aplicabilidade direta e imediata por juízes e tribunais". Para Souza (4) tais garantias mostram que o Estado deve antes de disponibilizar tecnologias à sociedade, avaliá-las, para "atestar sua qualidade, eficácia e segurança", de modo a atingir o fim social.

A atuação do Poder Judiciário, ao definir que a Administração Pública conceda ações e serviços "procura realizar a promessa constitucional de prestação universal do serviço de saúde" (3), que é um dos princípios do Sistema Único de Saúde (SUS).

Nesse contexto, o indivíduo que não vê sua necessidade em saúde atendida diretamente pelo Poder Executivo, recorre ao Poder Judiciário na intenção de ter contemplado seu pedido. Esse conjunto de ações judiciais que tramitam pelos tribunais, ficou comumente conhecido como judicialização da saúde. Contudo, os pleitos das ações 
judiciais são cercados de complexidades próprias da área de saúde e uma delas refere à segurança dos pacientes na dispensação e uso de medicamentos.

A Administração Pública estabelece regras para o fornecimento de medicamentos à sociedade, de modo a garantir a eficácia, proteção e segurança do paciente na promoção, prevenção e tratamento de suas condições de saúde. A Lei $n^{\circ}$ 6.360/76 (5) instituiu que medicamentos, e outros produtos de saúde, químicos e cosméticos, inclusive os importados, não poderão ser industrializados e disponibilizados para consumo, sem antes obter o registro no órgão competente, a Agência Nacional de Vigilância Sanitária (Anvisa).

Conforme conferido pela Lei o 9.782/99 (6), compete também à Anvisa, o controle sanitário da produção, comercialização, fiscalização, e a edição de atos normativos infralegais que estabelecem as exigências de cumprimento as condições técnicas indispensáveis "para a comprovação da eficácia terapêutica e segurança do medicamento, elementos indispensáveis para o registro" (4).

Tal afirmativa é corroborada por Coli Nogueira (7) quando indica que a ausência do registro, colabora para a carência de monitoramento e avaliação das contraindicações ocorridas durante o consumo do fármaco e que cabe a "Anvisa proibir o uso do medicamento que se mostrou impróprio e prejudicial à saúde do indivíduo". Assegura ainda que, a ausência de registro nacional impossibilita o controle de preço e a regulação sanitária no país.

Apresentada a atuação da Administração acerca do registro de medicamentos, cabe também demonstrar a posição da Corte Suprema do Brasil, sobre o assunto. A audiência pública $n^{\circ} 04^{3}$, convocada pelo Supremo Tribunal Federal (STF) e presidida pelo Ministro Gilmar Mendes, teve por objetivo ouvir especialistas sobre o assunto da judicialização da saúde e seus impactos para a saúde pública. Acerca da exigência de registro nacional de medicamentos, os discursos indicaram que é vedado à administração pública o fornecimento de fármaco que não possua registro na Anvisa, o que foi confirmado na Suspensão de Tutela Antecipada 175 do STF (8):

O registro de medicamento, como ressaltado pelo Procurador-Geral da República na Audiência Pública, é uma garantia à saúde pública. $\mathrm{E}$, como ressaltou o Diretor Presidente da ANVISA na mesma ocasião, a Agência, por força da lei de sua criação, também realiza a regulação econômica dos fármacos. Após verificar a eficácia, a segurança e a qualidade do produto e

\footnotetext{
${ }^{3}$ Audiência Pública sobre judicialização da saúde e seus reflexos na área da saúde. [Internet]. [Acesso em: 27 de out. de 2015]. Disponível em: http://www.stf.jus.br/arquivo/cms/processoAudienciaPublicaSaude/anexo/Abertura.pdf
} 
conceder-Ihe o registro, a ANVISA passa a analisar a fixação do preço definido, levando em consideração o benefício clínico e o custo do tratamento.

Para o ministro Gilmar Mendes, o registro nacional tem características fundamentais para "atestar a segurança e o benefício do produto, sendo o primeiro requisito para que o Sistema Único de Saúde possa considerar sua incorporação" (8).

Para colaborar com os magistrados na análise e decisão das ações judiciais sobre medicamentos sem registro nacional, o CNJ editou a Recomendação $n^{\circ} 31$ de março de 2010 (9) indicando análise mais aprofundada do caso concreto, a fim de evitar o "fornecimento de medicamentos sem registro nacional ou em fase experimental, ressalvada as exceções expressas em lei".

Posteriormente, em abril de 2010, o CNJ publicou a Resolução n 107 (10), que instituiu o Fórum Nacional do Judiciário para monitorar as resoluções de demandas judiciais do direito à saúde, sejam aquelas relacionadas ao SUS ou relacionadas à saúde suplementar. Compete ainda relatar que esse órgão de governança do poder judiciário, realizou nos anos 2014 e 2015, jornadas de direito sanitário com a emissão de enunciados interpretativos sobre saúde coletiva, suplementar e biodireito.

Para esse artigo interessam os enunciados números $04^{4}, 06^{5}, 09^{6}$ e $12^{7}$, que dizem respeito ao fornecimento de medicamentos sem registro nacional ${ }^{8}$.

O SUS, a partir das 3 esferas de gestão, estabelece suas políticas de medicamentos a partir da eficácia, segurança, evidências clínicas, existência de registro nacional e custoefetividade. Uma análise feita pela Comissão Nacional de Incorporação de Tecnologias no

\footnotetext{
${ }^{4}$ Enunciado n4 - Os Protocolos Clínicos e Diretrizes Terapêuticas (PCDT) são elementos organizadores da prestação farmacêutica, e não limitadores. Assim, no caso concreto, quando todas as alternativas terapêuticas previstas no respectivo PCDT já tiverem sido esgotadas ou forem inviáveis ao quadro clínico do paciente usuário do SUS, pelo princípio do art. 198, III, da CF, pode ser determinado judicialmente o fornecimento, pelo Sistema Único de Saúde, do fármaco não protocolizado.

${ }^{5}$ Enunciado $n^{\circ}$ 6- A determinação judicial de fornecimento de fármacos deve evitar o fornecimento de medicamentos ainda não registrados na ANVISA, ou em fase experimental, ressalvadas as exceções expressamente previstas em lei.

${ }^{6}$ Enunciado $n^{\circ}$ 9- As ações que versem sobre medicamentos e tratamentos experimentais devem observar as normas emitidas pela Comissão Nacional de Ética em Pesquisa (CONEP) e Agência Nacional de Vigilância Sanitária (ANVISA), não se podendo impor aos entes federados provimento e custeio de medicamento e tratamentos experimentais.

${ }^{7}$ Enunciados $n^{\circ} 12$ - A inefetividade do tratamento oferecido pelo SUS, no caso concreto, deve ser demonstrada por relatório médico que a indique e descreva as normas éticas, sanitárias, farmacológicas (princípio ativo segundo a Denominação Comum Brasileira) e que estabeleça o diagnóstico da doença (Classificação Internacional de Doenças), tratamento e periodicidade, medicamentos, doses e fazendo referencia ainda sobre a situação do registro na ANVISA (Agência Nacional de Vigilância Sanitária).

I J Jornada de Direito da Saúde. Conselho Nacional de Justiça. [Internet]. [Acesso em 2015, 8 de novembro]. Disponível em:

http://www.cnj.jus.br/images/ENUNCIADOS APROVADOS NA JORNADA DE DIREITO DA SAUDE \%20PLENRIA 1 55 14 r.pdf.
} 
SUS (CONITEC) ${ }^{9}$ pode sugerir ou não, a incorporação daquela tecnologia no sistema público (11), o que é apreciado pelo Ministério da Saúde. Os medicamentos incorporados são apresentados na Relação Nacional de Medicamentos (RENAME) (12), originada da Política Nacional de Medicamentos, publicada em 2001 (13).

Interessa apresentar também os Protocolos Clínicos e Diretrizes Terapêuticas (PCDT), cujo conceito é de Mendes:

Documento que estabelece critérios para o diagnóstico; tratamento; posologia e acompanhamento e verificação dos resultados além de efetivarem o papel fundamental para os processos de gerenciamento dos programas farmacêuticos no Brasil, e nos processos educacionais em saúde incluindo os profissionais e pacientes do sistema de saúde, nos aspectos legais envolvidos no processo de fornecimento de medicamentos e insumos terapêuticos (14).

Os Protocolos Clínicos e Diretrizes Terapêuticas norteiam a assistência médica e farmacêutica, além de auxiliar os gestores como instrumento de apoio na disponibilização de procedimentos e na tomada de decisão quanto à aquisição e dispensação de medicamentos. Santos (15) expõe a necessidade dos PCDT alcançarem a argumentação jurídica, fundamentalmente nos "casos onde o pedido seja de fármacos não reconhecidos e não incorporados pelo SUS, ou que ainda que sejam experimentais".

Recentemente, a mídia naciona ${ }^{10}$ discutiu a concessão de medicamento sem registro nacional, na judicialização da saúde. Trata-se do caso da substância fosfoetanolamina, pesquisada pelo Instituto de Química da Universidade de São Paulo (USP), anunciada como cura para o câncer.

O Tribunal de Justiça do Estado de São Paulo foi provocado a manifestar-se sobre o assunto e decidiu suspender o fornecimento da substância, por faltar-lhe evidências e outros requisitos exigidos para o registro nacional. O mesmo caso foi levado ao STF, que entendeu de forma diversa e permitiu que a substância fosse concedida aos pacientes que a requisitaram judicialmente ${ }^{11}$. Em análise do caso, a professora de direito constitucional

\footnotetext{
${ }^{9}$ Brasil. Lei Federal $n^{\circ} 7.646$ de 21 de dezembro de 2011. Dispõe sobre a Comissão Nacional de Incorporação de Tecnologias no Sistema Único de Saúde e sobre o processo administrativo para incorporação, exclusão e alteração de tecnologias em saúde pelo Sistema Único de Saúde - SUS, e dá outras providências. [Internet]._ [Acesso em 2015, 9 de novembro]. Disponível em: http://www.planalto.gov.br/ccivil 03/ Ato2011-2014/2011/Decreto/D7646.htm

10 Entre outros: Site G1. Notícia: Apresenta um alerta sobre cápsulas distribuídas como cura do câncer. [Internet]. [Acesso em 2015, 30 de outubro]. Disponível em: http://g1.globo.com/fantastico/noticia/2015/10/drauzio-varella-alertasobre-capsulas-distribuidas-como-cura-do-cancer.html.

11 Notícia jornalística do TJSP sobre o assunto.
} 
da Universidade de Brasília (UnB), Penalva (16) afirma que a decisão do Ministro do STF, Luiz Edson Fachin, está equivocada na medida em que compara o pleito pela substância Fosfoetanolamina com o expresso no Recurso Extraordinário (RE) 657.718/MG ${ }^{12}$.

O caso do RE 657.718/MG refere processo em que foi solicitado medicamento sem registro nacional e sobre o qual foi reconhecida Repercussão Geral ${ }^{13}$ e que aguarda decisão da Suprema Corte acerca da tese: "em se tratando de remédio não registrado na Agência Nacional de Vigilância Sanitária ANVISA há a obrigatoriedade de o Estado o custear? ", que passará a balizar todos os tribunais brasileiros.

Em que pese grande parte do artigo encontrar fundamento nas premissas constituídas para a saúde pública (SUS), a saúde suplementar - regulada pela Lei ำ 9.961, de 28 de janeiro de 2000 (17) também é condenada ao cumprimento de decisões judiciais que deferem a concessão de medicamentos sem registro nacional, ainda que a já mencionada lei, em seu artigo 10, V, proíba tal prática.

\section{Metodologia}

O presente artigo foi elaborado a partir da análise de dados qualiquantitativos, apresentados de forma descritiva analítica, considerada a extração e leitura de acórdãos ${ }^{14}$ do TJDFT que referem pleitos por medicamentos sem registro nacional - nos anos 2013 a 2015, a partir da utilização dos seguintes descritores: (1) Medicamentos sem registro, (2) SUS, (3) Não padronizados.

Tratou-se de base de dados pública, acessível livre e desembaraçadamente por qualquer interessado (18), constituindo pesquisa fundamentada totalmente em dados secundários.

Primeiramente, foi pesquisado exclusivamente o descritor "Medicamentos sem registro", o que resultou em 71 acórdãos. Em segunda busca foi acrescido o segundo

Disponível em http://www.tjsp.jus.br/institucional/canaiscomunicacao/noticias/Noticia.aspx?ld=28335. [Internet]. [Acesso em 2015, 30 de outubro].

12 Sobre o RE 657.718/MG. [Internet]. [Acesso em 2015, 30 de outubro].

Disponível emhttp://www.stf.jus.br/portal/processo/verProcessoAndamento.asp?incidente $=4143144$.

13 A Repercussão Geral é regida pela Lei n. 11.418 de 19.12.06 e a Resolução/ STF 417/09.

14 Acórdãos são as decisões colegiadas dos tribunais. O julgamento é o ato de decidir o processo e o acórdão é o documento escrito, composto pelo relatório e pelos votos de todos os Ministros que tenham participado do julgamento, que é efetivamente juntado ao processo. [Internet]. [Acesso em 2015, 8 de novembro].

Disponível em: http://www.stf.jus.br/portal/cms/verTexto.asp?servico=estatistica\&pagina=entendadecisoes. 
descritor "SUS" e foram encontrados 18 acórdãos. O terceiro descritor, "não padronizados", foi inserido na base de dados, em conjunto com os outros dois, apresentando como resultado 17 acórdãos. Essa estratégia foi utilizada uma vez que o primeiro descritor, utilizado de forma isolada, possibilitou achados que referiram o sistema público e privado. O segundo descritor pormenorizou os achados do sistema público e o terceiro deu-se em decorrência de expressão comumente encontrada nos acórdãos resultados de busca já realizada.

Portanto, foram identificados 106 (cento e seis) acórdãos acerca de pedidos de medicamento sem registro na Anvisa. Nesse contexto, é preciso esclarecer que não foram considerados processos que porventura corram em segredo de justiça, por não estarem publicizados.

Dos 106 acórdãos inicialmente encontrados, a partir de leitura flutuante (19), foram selecionados 26 (vinte e seis). Foram incluídas todas as decisões judiciais que referiram: (i) ações individuais; (ii) pleito por medicamento identificado como sem registro nacional; (iii) publicação nos anos 2013, 2014 e 2015 (até setembro); (iv) SUS ou Plano ou Seguro de Saúde (Saúde Suplementar); (v) algum dos descritores, excluindo-se os demais acórdãos.

Foram utilizadas, como material auxiliar e para dar fundamento aos achados, publicações, quer em capítulos de livros ou artigos científicos, levantamento da legislação, posicionamentos da agência reguladora nacional (Anvisa), decisão da STA 175 do STF e enunciados do CNJ, que refiram registro nacional de medicamentos.

Destaca-se que não é do escopo dessa pesquisa, a análise da aferição do objeto pleiteado judicialmente e as competências estabelecidas na política pública, como forma de indicar a legitimidade processual do ente público, menos ainda, qualquer referência acerca da solidariedade entre entes. A pesquisa refere-se exclusivamente à utilização dos argumentos da STA 175 do STF e dos enunciados do CNJ, afetos aos medicamentos sem registro no Brasil, por qualquer das partes envolvidas no processo (Distrito Federal, usuários e magistrados).

Coletados e organizados os dados, foram elaborados gráficos para apresentação didática de conteúdo e facilitação de análise, em especial, a discussão acerca da incidência dos enunciados 04, 06, 09 e 12 do CNJ e da decisão da STA 175 do STF, nas decisões judiciais do Tribunal de Justiça do Distrito Federal e Territórios (TJDFT). 


\section{Resultados e Discussão}

Quanto aos achados, compete a observação do gráfico 1:

Gráfico 1: Acórdãos Proferidos pelo TJDFT em processos que referem Medicamento Sem Registro Nacional - 2013-2015

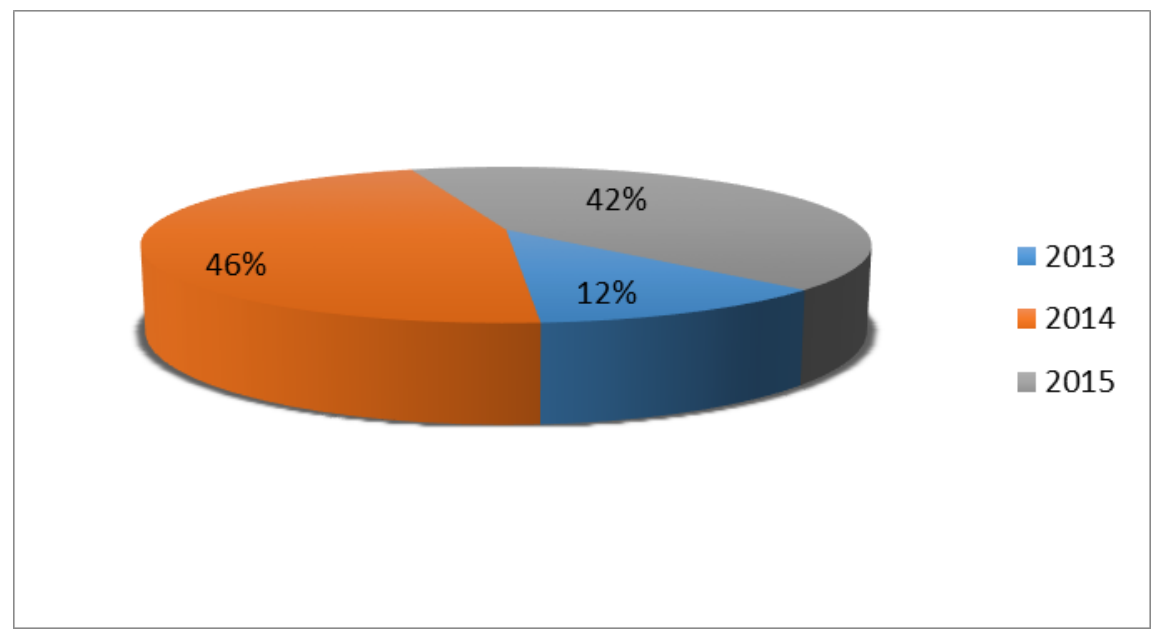

Fonte: Elaborado com base em consulta dos acórdãos- TJDFT, 2013-2015.

Foram encontrados 26 acórdãos quando somados os 3 anos pesquisados, sabendo que o último ano foi considerado até o mês de setembro. O ano de 2013, do cômputo total, contou com 12\% de processos; o ano 2014 contou com 46\%; e, $201542 \%$. Esses dados identificam que um número cada vez maior de processos por medicamentos sem registro na Anvisa chega à instância recursal, o que pode denotar, um aumento da demanda. Essa afirmativa tem respaldo quando comparados os anos 2013 e 2014 e ainda, quando considerada a proporcionalidade do ano 2015, em face dos anos anteriores.

A título de informações gerais, outro dado interessante revela que $62,96 \%$ dos recursos apresentados para apreciação do TJDFT, foram deferidos em favor do usuário do sistema público de saúde. Os argumentos apresentados pelo DF, como parte na ação, são fundados em leis federais, tais como a Lei 8.080/90, artigo $6^{\circ}$, inciso I (20), que versa o campo de atuação do SUS ou ainda, o que the foi posteriormente acrescentado pela Lei 12.401/11 (21), no que diz respeito aos PCDT.

Observados os fundamentos apresentados pelos usuários do SUS, para contraditar os fundamentos do recurso apresentado pelo DF, em $29,63 \%$ do total de acórdãos, foi 
explicitado o uso dos argumentos: "direito à vida", "dignidade da pessoa humana" e o "artigo 196 da CF/88" (1) e ainda o artigo 204 da Lei Orgânica da Saúde do Distrito Federal (DF) (22).

Do total de acórdãos analisados, 7,41\% referiram à saúde suplementar e têm o Plano ou Seguro Saúde apresentando recurso sobre sentença que the tenha determinado concessão ou pagamento de valores referentes aos medicamentos sem registro na Anvisa e ainda, com relação ao dano moral causado ao beneficiário. Os fundamentos apresentados pelos Planos/Seguradoras referem, crime tipificado no Código Penal o fornecimento do fármaco.

Ultrapassadas as linhas gerais, nos acórdãos analisados, cabe apresentar o gráfico 2:

Gráfico 2: Utilização dos argumentos existentes na STA 175 do STF e Enunciados do CNJ nos acórdãos analisados, para deferir ou não a concessão de medicamentos sem registro nacional, a partir de recursos apresentados pelo Distrito Federal (DF) ${ }^{15}$.

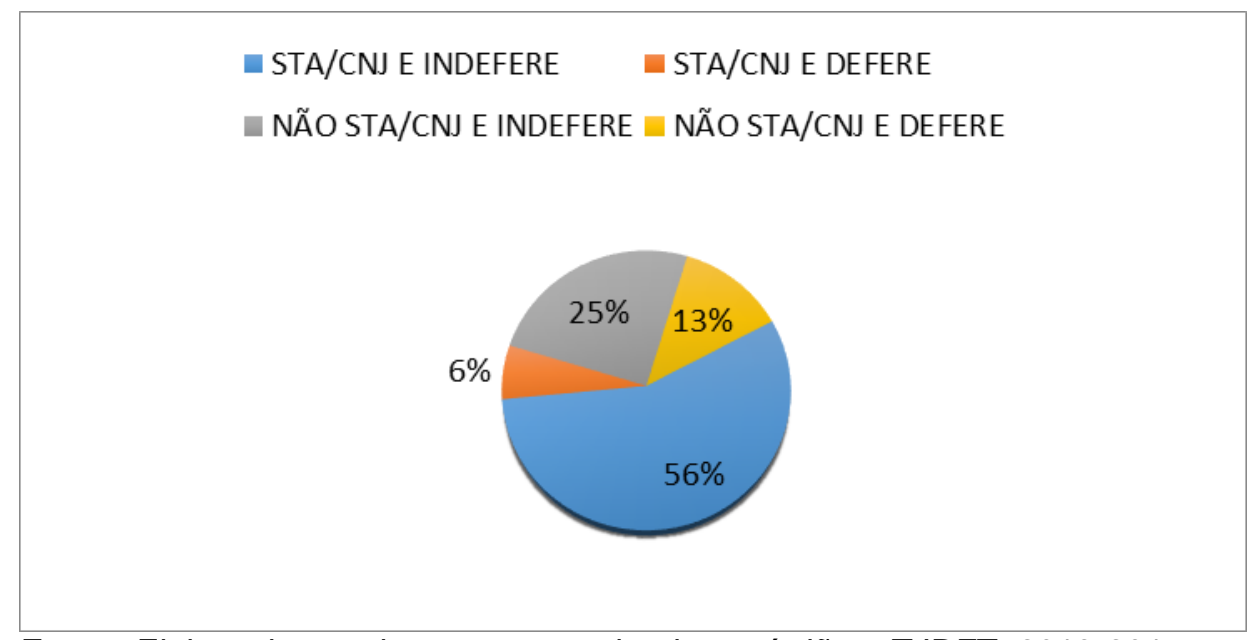

Fonte: Elaborado com base em consulta dos acórdãos- TJDFT, 2013-2015.

Os dados revelam que em $81 \%$ dos processos recorridos pelo DF, houve deferimento da concessão do medicamento sem registro nacional, sendo que desses, em $56 \%$ dos acórdãos há citação da STA 175 e enunciados do CNJ como fundamento para os acórdãos. No mesmo raciocínio, a não concessão do medicamento sem registro nacional

\footnotetext{
${ }^{15}$ Segundo o gráfico II, os $53 \%$ correspondem aos acórdãos $n^{\circ} 841247, n^{\circ} 877668, n^{\circ} 877258, n^{\circ} 841242, n^{\circ}$ $831783, n^{\circ} 786696, n^{\circ} 782795, n^{\circ} 894347$ e $n^{\circ} 851943$; os $29 \%$ correspondem aos acórdãos $n^{\circ} 886151, n^{\circ}$ 884481 e $n^{\circ} 865957$. 12\% correspondem aos acórdãos $n^{\circ} 857727$ e $n^{\circ} 692013$; e, os $6 \%$ corresponde ao acórdão $n^{\circ} 825837$.
} 
ocorreu em $19 \%$ do total de acórdãos e desses, em $6 \%$ a STA 175 foi utilizada como fundamento da decisão.

Nesse âmbito cabe apresentar a consideração de Silva (23), para quem a prática mostra a insuficiência dos parâmetros traçados para resolver os pleitos apresentados ao Poder Judiciário, que se referem a medicamentos sem registro na Anvisa. Para a autora, o judiciário é visto como pacificador de conflitos de interesses e, acaba exercendo papel de controle judicial das escolhas feitas pelo administrador.

Considerando que o maior percentual dos acórdãos se vale da decisão STA 175 e enunciados do CNJ para conceder medicamentos sem registro nacional, cabe demonstrar, as interpretações dadas à decisão do STF, pelos desembargadores do TJDFT. Cite-se, do acórdão n 643755 , de janeiro de 2013:

Não há que se falar, no caso, em impedimento absoluto, derivado da Lei 12.401/2011, que alterou a Lei 8.080/1990, de fornecimento de medicamento não registrado pela ANVISA, pois a vedação ali contemplada dirige-se a todas as esferas de gestão do SUS, não impedindo que possa o Judiciário, avaliando uma situação concreta e ponderando os bens e valores em conflito deixar de aplicar a referida vedação, privilegiando-se o valor de proteção à saúde de estatura constitucional, conforme entendimento do STF (Suspensão de tutela antecipada $n^{\circ} 175$, DJe 182 de 28.09.09) ${ }^{16}$ (grifo nosso).

Dos acórdãos que não mencionam a decisão STA 175 e os enunciados do CNJ e que corresponderam a $25 \%$ dos casos de concessão do medicamento sem registro, cabe apresentar, que seus fundamentos trazem expressões como "a falta do medicamento pode acarretar iminente risco à saúde do paciente" "17, "o tratamento adequado lhe traz esperança de vida" ${ }^{18}$.

\footnotetext{
${ }^{16}$ Brasília. Tribunal de Justiça do Distrito Federal e Territórios. Mandado de Segurança n. 643755. Apelante: Leila Carmen. Apelado: Distrito Federal. Relator: Flavio Rostirola. Janeiro, 2013. Jurisprudência do TJDFT. Brasília-DF, nov. 2015.

${ }_{17}$ Brasília. Tribunal de Justiça do Distrito Federal e Territórios. Mandado de Segurança n. 884481. Apelante: Distrito Federal. Apelado: Tania Mara Mascarenhas de Carvalho. Relator: Carlos Rodrigues. Julho, 2015. Jurisprudência do TJDFT. Brasília-DF, nov. 2015.

${ }_{18}$ Brasília. Tribunal de Justiça do Distrito Federal e Territórios. Mandado de Segurança n. 884481. Apelante: Distrito Federal. Apelado: Silvia Cristina Lacerda. Relator: Alfeu Machado. Janeiro, 2014. Jurisprudência do TJDFT. Brasília-DF, nov. 2015.
} 
No acórdão $n^{\circ} 886151^{19}$ há menção de que tanto a doutrina, quanto a jurisprudência reconhecem que o direito à preservação da saúde não pode ser interpretado como uma norma meramente programática. No caso que segue, o fundamento para a decisão judicial revela que o DF utilizou-se de argumentos específicos da política de saúde e que esses não foram considerados. Cite-se:

E na espécie, ainda que o Distrito Federal destaque que o remédio não esteja inserido na lista de medicamentos autorizados junto à Secretaria de Saúde [...], tampouco na relação nacional de medicamentos, tal situação, registre-se, de forma excepcional que o caso requer, não constituiria no presente caso, óbice para que o Estado forneça o tratamento.

Ainda em sede de debates e da demonstração da complexidade do tema, o mesmo acórdão 886151, com fundamento nos artigos 196 da CF/88 (1), 204 e 207 da Lei Orgânica da Saúde do DF (22), decidiu que:

O direito a saúde é dever do Agravante, de sorte que a Agravada, munida de relatório médico demonstrando a necessidade do fármaco, sob pena de ver tolhido o seu direito à saúde ou mesmo à vida.

Para a desembargadora tais direitos se sobrepõem em casos excepcionais que tratam de doenças graves e raras a qualquer norma infralegal. Considerando os fundamentos do acórdão, cumpre novamente recorrer à Silva (23), quando diz que é:

Imprescindível que os Tribunais pautem sua atuação não apenas nas circunstâncias fáticas peculiares do caso concreto, mas também observando o conteúdo das políticas públicas de saúde, no intercâmbio de informações e na promoção do fornecimento de mecanismos institucionais e multidisciplinares para a solução das demandas deste quilate.

Esses relatos podem denotar o quanto ainda é insuficiente, de forma geral, a relação do judiciário e a administração pública no que tange as complexidades da prestação dos serviços em saúde (14). Nesse ponto do debate, cabe referir á posição de Coli Nogueira (7):

Quando se busca resolver o acesso aos medicamentos pela via judicial, o que se está fazendo, é ignorar todo o processo de incorporação tecnológica dos novos medicamentos, que deve ser feita pela ótica da melhor medicina e não como base unicamente na opinião isolada do médico prescritor, muitas vezes sob a influência e pressão da indústria farmacêutica, ignorando o consenso científico e da melhor evidência, que apontem um caminho mais seguro, ainda que seja pela não liberação do registro pleiteado.

\footnotetext{
${ }^{19}$ Brasília. Tribunal de Justiça do Distrito Federal e Territórios. Agravo de Instrumento n. 886151. Apelante: Distrito Federal. Apelado: Maria de Lurdes. Relatora: Gislene Pinheiro. Agosto, 2015. Jurisprudência do TJDFT. Brasília-DF, nov. 2015.
} 
Acerca da legitimação da prescrição médica, cabe mencionar o enunciado $n^{\circ} 12^{20}$ do CNJ que indica a necessidade de relatório circunstanciado sobre as condições clínicas do paciente, refutando mera prescrição sem apresentação de fundamentos.

Sobre a legitimação dos "certificados de eficácia em outros países", vale conhecer posicionamento de Penalva (16):

[...] indagar se a vigilância sanitária é pressuposto para o fornecimento de medicamentos é indagar se as ações de eliminação, diminuição e prevenção à saúde são dimensões do próprio direito à saúde. A análise de segurança, qualidade e a fixação de preço do produto são necessárias para à garantia do direito à saúde.

Em relação aos 13\% dos acórdãos em que, apesar de não haver menção a STA 175 ou aos enunciados do $\mathrm{CNJ}$, foi negada a concessão de importação de medicamento sem registro nacional nos casos em que a prescrição superava ao permitido nas normas da agência reguladora, contudo, autorizando que fosse importado o limite previsto. $O$ acórdão $n^{\circ} 857727^{21}$ asseverou que "não há óbice legal para a importação do medicamento, na concentração permitida, e a sua dispensa ao autor".

Os $6 \%$ dos acórdãos analisados, fundamentos a partir da STA175 e dos enunciados do $\mathrm{CNJ}$, serviram para indeferir a concessão de medicamentos sem registro no Brasil. $\mathrm{O}$ acórdão que compõe esse percentual é $n^{\circ} 825837^{22}$ menciona que não foi demonstrada pelo prescritor, a inefetividade do tratamento oferecido pelo SUS. O acórdão identificado assevera:

A ausência do registro junto à Agência Nacional de Vigilância Sanitária configura óbice à aquisição do medicamento em questão, uma vez que o seu ingresso no território nacional (importação de medicamento não registrado na ANVISA) configura crime tipificado no Código Penal Brasileiro (Art. 273, $\S 1^{\circ}-\mathrm{B}, \mathrm{I}$, do CP), conforme vem decidindo o egrégio Superior Tribunal de Justiça.

\footnotetext{
${ }^{20}$ Enunciados $n^{\circ} 12-\mathrm{A}$ inefetividade do tratamento oferecido pelo SUS, no caso concreto, deve ser demonstrada por relatório médico que a indique e descreva as normas éticas, sanitárias, farmacológicas (princípio ativo segundo a Denominação Comum Brasileira) e que estabeleça o diagnóstico da doença (Classificação Internacional de Doenças), tratamento e periodicidade, medicamentos, doses e fazendo referencia ainda sobre a situação do registro na ANVISA (Agência Nacional de Vigilância Sanitária).

${ }^{21}$ Brasília. Tribunal de Justiça do Distrito Federal e Territórios. Apelação n. 857727. Apelante: Distrito Federal. Apelado: Arthur Rocha. Relator: Fernando Habibe. Março, 2015. Jurisprudência do TJDFT. Brasília-DF, nov. 2015.

${ }^{22}$ Brasília. Tribunal de Justiça do Distrito Federal e Territórios. Apelação n. 825837. Apelante: Distrito Federal. Apelado: Luís Fernando. Relator: Ângelo Passareli. Outubro, 2014. Jurisprudência do TJDFT. Brasília-DF, nov. 2015.
} 
Gráfico 3: Utilização dos argumentos existentes na STA 175 do STF e Enunciados do CNJ nos acórdãos analisados, para deferir ou não a concessão de medicamentos sem registro nacional, a partir de recursos apresentados pelos usuários do SUS.

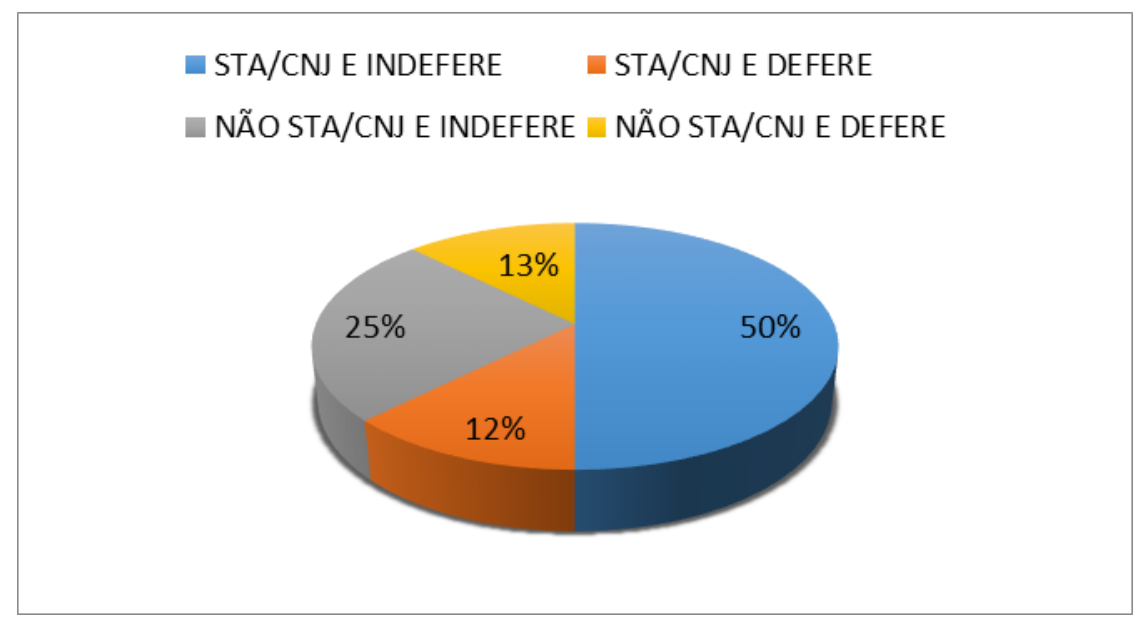

Fonte: Elaborado com base em consulta dos acórdãos- TJDFT, 2013-2015.

Em 50\% dos acórdãos analisados, a partir de recursos apresentados pelos usuários do SUS, a STA 175 serviu de fundamento para o indeferimento do pleito por medicamentos sem registro na Anvisa. O acórdão $655207^{23}$ expressa que "não pode o Poder Judiciário desconsiderar políticas públicas já implementadas". Reconhece que esse é um conflito que deve ser analisado caso a caso, com as devidas ponderações entre princípios e leis:

[...] juridicamente o fornecimento, por via judicial, de medicamento que não possua 0 devido registro na ANVISA, constitui-se em provimento jurisdicional ilegal, nos termos do art. 12 da Lei $n^{\circ} 6.360 / 1976 \mathrm{c} / \mathrm{c}$ Art. 19-T da Lei 8.080/1990, alterada pela Lei 12.401 de 28 de abril de 2011 (grifo nosso).

Já o acórdão $n^{\circ} 877726^{24}$ afirma que a ausência de registro junto ao órgão competente (Anvisa) configura óbice à aquisição do fármaco - conforme a STA 175 -e acrescenta que a importação de medicamentos sem registro em território nacional trata de crime tipificado no código penal.

\footnotetext{
${ }^{23}$ Brasília. Tribunal de Justiça do Distrito Federal e Territórios. Embargos de Declaração n. 655207. Apelante: Leila Carmen. Apelado: Distrito Federal. Relator: Flavio Rostirola. Fevereiro, 2013. Jurisprudência do TJDFT. Brasília-DF, nov. 2015.

${ }^{24}$ Brasília. Tribunal de Justiça do Distrito Federal e Territórios. Agravo de Regimento n. 877726. Apelante: Gilson Azolino. Apelado: Distrito Federal. Relator: Flavio Rostirola. Fevereiro, 2013. Jurisprudência do TJDFT. Brasília-DF, nov. 2015.
} 
No acórdão n $643755^{25}$, é mencionado pelo juiz a consideração do controle de preço efetuado pela Anvisa no momento do registro do produto, e que tal carência dificulta a apreciação dos medicamentos pela Administração pública.

No conjunto que refere $25 \%$ dos acórdãos que não mencionaram a STA 175 e nem as recomendações do $\mathrm{CNJ}$, para justificar negativa à concessão de medicamento sem registro nacional, os argumentos encontraram guarida na Lei $n^{\circ} 6.360 / 76$, artigo 12(5). O Acórdão $838724^{26}$ estabeleceu que "nenhum produto, inclusive medicamentos, poderá ser industrializado, exposto à venda ou entregue ao consumo antes de registro no Ministério da Saúde". Já o acórdão $n^{\circ} 847226^{27}$ indicou como fundamento a Lei $n^{\circ}$ 12.401/11, que alterou a lei orgânica da saúde, no artigo 19-T e que reitera a vedação do fornecimento de medicamentos não registrados na Anvisa.

Observados os acórdãos que correspondem aos $13 \%$ e não se valem da STA 175 , nem dos enunciados CNJ para a concessão do medicamento sem registro nacional - a partir dos recursos apresentados pelos usuários do SUS - vale apresentar a compreensão do acórdão $n^{\circ} 847226^{28}$ cuja decisão descreve que negar o tratamento pretendido, por mais que não atenda aos PCDT do Ministério da Saúde, em face da inexistência de outro tratamento eficaz, significa pactuar com a violação à integridade e dignidade da pessoa humana em condição de fragilidade, conferindo preponderância às limitações normativas subalternas, o que é impensável e impraticável no âmbito da função jurisdicional do Estado, que é precisamente denunciar a injustiça e realizar o direito.

A representação de $12 \%$ dos acórdãos utiliza-se dos fundamentos da STA 175 para a concessão do medicamento sem registro no Brasil, e o acórdão $n^{\circ} 786663^{29}$ ressalta que paciente portador de doença rara e grave, merece raciocínio diferenciado quanto ao

\footnotetext{
${ }^{25}$ Brasília. Tribunal de Justiça do Distrito Federal e Territórios. Mandado de Segurança n. 643755. Apelante: Leila Carmen. Apelado: Distrito Federal. Relator: AngeloPassareli. Julho, 2015. Jurisprudência do TJDFT. Brasília-DF, nov. 2015.

${ }^{26}$ Brasília. Tribunal de Justiça do Distrito Federal e Territórios. Mandado de Segurança n. 838724. Apelante: Leandro de Borja. Apelado: Distrito Federal. Relator: Jair Soares. Dezembro, 2014. Jurisprudência do TJDFT. Brasília-DF, nov. 2015.

${ }^{27}$ Brasília. Tribunal de Justiça do Distrito Federal e Territórios. Agravo de Instrumento n. 847226. Apelante: Antonia Ferreira. Apelado: Distrito Federal. Relator: AngeloPassareli. Fevereiro, 2015. Jurisprudência do TJDFT. Brasília-DF, nov. 2015.

${ }^{28}$ Brasília. Tribunal de Justiça do Distrito Federal e Territórios. Agravo de Instrumento n. 847226. Apelante: Antonia Ferreira. Apelado: Distrito Federal. Relator: AngeloPassareli. Fevereiro, 2015. Jurisprudência do TJDFT. Brasília-DF, nov. 2015.

${ }^{29}$ Brasília. Tribunal de Justiça do Distrito Federal e Territórios. Agravo de Instrumento n. 786663. Apelante: Rodrigo de Oliveira. Apelado: Distrito Federal. Relator: Flavio Rostirola. Abril, 2014. Jurisprudência do TJDFT. Brasília-DF, nov. 2015.
} 
fornecimento do medicamento, ao afirmar que a regra do não fornecimento do medicamento sem registro na Anvisa, não é absoluta, e que em casos excepcionais a importação de medicamentos não registrado poderá ser autorizado.

Por fim, observado o conteúdo dos $7.41 \%$ dos acórdãos que se referem a saúde suplementar: os fundamentos que indeferiram recursos interpostos pelos planos e seguradoras não se valeram da STA 175 e nem dos enunciados CNJ - fundamentando-se na legislação que refere relação de consumo. Para ilustrar, cabe mencionar o acórdão $n^{\circ}$ $812398^{30}$ que afirma que o risco à vida não pode ser preterido para privilegiar interesse patrimonial.

\section{Considerações Finais}

Por tudo que se apresentou, importa reafirmar o quão é complexa a discussão que envolve a solicitação judicial de medicamentos sem registro nacional e põe em confronto argumentos de diversas ordens.

Se de um lado há apresentação de regramentos legais sobre o fornecimento de medicamentos registrados na Anvisa, padronizados, incorporados ao SUS, com eficácia e segurança verificadas e atestadas, com preço regulado pelo Estado brasileiro, de outro há um direito à saúde que ultrapassa os dispositivos infralegais, a liberdade de prescrição do profissional médico, etc.

É possível inferir que tanto a STA 175, quanto os enunciados do CNJ indicam o não fornecimento de medicamentos não registrados no Brasil, muito embora, a maioria dos acórdãos defere os argumentos apresentados pelos usuários, sem referir-se aos aspectos da segurança do paciente, do controle de preços no mercado ou ainda da tipificação criminal.

Percebe-se, contudo, que os argumentos trazidos em segunda instância e notadamente utilizados nos acórdãos estudados, revelam um aprofundamento nas discussões sobre o direito à saúde. Para além dos dispositivos constitucionais, há um elenco de regramentos e disciplinas do direito à saúde apresentados ao debate, sendo ampla e continuamente discutidos.

\footnotetext{
${ }^{30}$ Brasília. Tribunal de Justiça do Distrito Federal e Territórios. Agravo de Instrumento n.812398. Apelante: Sul America Seguradora de Saúde. Apelado: Afonso Ubirajara. Relator: Gilberto Pereira. Agosto, 2014. Jurisprudência do TJDFT. Brasília-DF, nov. 2015.
} 
De forma incontestável a pesquisa é capaz de revelar a insuficiência de parâmetros para as decisões judiciais atualmente apreciadas, o que requer, na análise do caso concreto, capacidade de ponderação pelo magistrado, dos diferentes argumentos apresentados, quer pela Administração Pública, quer pelo usuário, quer pelo Plano/Seguro de Saúde.

Dessa forma é de crucial importância a decisão do STF acerca da repercussão geral sobre o fornecimento de medicamentos sem registro nacional, como forma de ofertar parâmetros para as decisões e disciplinar o assunto debatido nesse artigo, nos casos posteriormente considerados pelos tribunais de justiça.

Essa não é uma pesquisa que pode ser extrapolada, deve ser compreendida em seu contexto geograficamente restrito, mas ela é suficiente para demonstrar a necessidade de que se pesquise acerca das decisões judiciais sobre medicamentos sem registro, em nível nacional, com vistas a oferecer informação - hoje não evidente - aos tomadores de decisão, de qualquer dos poderes.

\section{Referência}

1 Brasil. Constituição da República Federativa do Brasil de 5 de outubro de 1988. [Internet] Brasília: Senado Federal, 2011. [Acesso em 8 nov 2015]. Disponível em http://www.planalto.gov.br/ccivil 03/constituicao/ConstituicaoCompilado.htm.

2 Ana, KTTN. A judicialização pelo Ministério Público Federal do Direito à Saúde. In: Delduque MC; Alves SMC; Netto ND, organizadores. Direito Sanitário em Perspectiva. Brasília-DF; 2015. p. 497-520.

3 Barroso LR. Da falta de efetividade à judicialização excessiva: direito à saúde, fornecimento gratuito de medicamentos e parâmetros para atuação judicial. Rio de Janeiro: 2007. [Acesso em 04 out 2015]. Disponível em:

http://www.conjur.com.br/dl/estudobarroso.pdf.

4 Souza MDC. Medicamentos sem registro e suas consequências. Conass, 2015. [Acesso em 2015, 04 de outubro]. Disponível em:

http://www.conass.org.br/biblioteca/pdf/colecao2015/CONASS-DIREITO A SAUDE-

ART 8B.pdf

5 Brasil. Lei Federal n. 6.360, de 23 de setembro de 1976. Dispõe sobre a Vigilância Sanitária a que ficam sujeitos os Medicamentos, as Drogas, os Insumos Farmacêuticos e Correlatos, Cosméticos, Saneantes e Outros Produtos, e dá outras Providências. [Acesso em 4 set 2015]. Disponível em: http://www.planalto.gov.br/ccivil 03/leis/l6360.htm. 
Vigilância Sanitária, cria a Agência Nacional de Vigilância Sanitária, e dá outras providências. [Acesso em 4 set 2015]. Disponível em: http://www.planalto.gov. br/ccivil_03/leis/l9782.htm.

7 Coli Nogueira M. Medicamento sem registro: Legislação, causas para a demanda, danos à saúde e consequências para a gestão. Conass, 2015. [Acesso em 4 set 2015]. Disponível em: http://www.conass.org.br/biblioteca/pdf/colecao2015/CONASSDIREITO A SAUDE-ART 26.pdf

8 Supremo Tribunal Federal. Suspensão de Tutela Antecipada 175. [Acesso em 10 out 2015]. Disponível em: http://www.stf.jus.br/arquivo/cms/noticianoticiastf/anexo/sta175.pdf.

9 Brasil. Conselho Nacional de Justiça. Recomendação n. 31 de 30 de março de 2010. Recomenda aos Tribunais a adoção de medidas visando a melhor subsidiar os magistrados e demais operadores do direito, para assegurar maior eficiência na solução das demandas judiciais envolvendo a assistência à saúde. [Acesso em 10 out 2015]. Disponível em: http://www.cnj.jus.br/atos-administrativos/atos-da-presidencia/322recomendacoes-do-conselho/12113-recomendacao-no-31-de-30-de-marco-de-2010.

10 Brasil. Conselho Nacional de Justiça. Resolução n. 107 de abril de 2010. Institui o Fórum Nacional do Judiciário para monitoramento e resolução das demandas de assistência à saúde. [Acesso em 4 set 2015]. Disponível em:

http://www.cnj.jus.br///images/atos normativos/resolucao/resolucao 1070604201011102 012191858.pdf.

11 Silva MMF. Da racionalidade das decisões judiciais nas demandas de fornecimento gratuito de medicamentos. In: Delduque MC; Alves SMC; Netto ND, organizadores. Direito Sanitário em Perspectiva. Brasília-DF; 2015. p. 608-626.

12 Ministério da Saúde. Relação Nacional de Medicamentos Essenciais. [Acesso em 8 nov 2015]. Disponível em: http://portalsaude.saude.gov.br/images/pdf/2014/julho/09/livrorename-2013-atualizado.pdf

13 Ministério da Saúde. Política Nacional de Medicamentos. [Acesso em 4 set 2015]. Disponível em: http://bvsms.saude.gov.br/bvs/publicacoes/politica medicamentos.pdf.

14 Mendes. JG. Análise de ações judiciais que envolvem pedidos de medicamentos não padronizados no sistema único de saúde: o caso do distrito federal. Universidade de Brasília, 2014.

15 Santos AO. Discursos proferidos na audiência pública da saúde do Supremo Tribunal Federal: uma análise à luz da teoria dos sistemas sociais. [Dissertação]. Brasília: Universidade de Brasília, 2013.

16 Penalva, J. Fosfoetanolamina: a quintessência da judicialização. [Acesso em 30 out 2015]. Disponível em: http://jota.info/fosfoetanolamina-a-quintessencia-da-judicializacao. 
17 Brasil. Lei Federal n. 9.961 de 28 de janeiro de 2000. Cria a Agência Nacional de Saúde Suplementar - ANS e dá outras providências. [Internet]. [Acesso em 2015, 30 de outubro]. Disponível em: http://www.planalto.gov.br/ccivil 03/Leis/L9961.htm

18 Site. Tribunal de Justiça do Distrito Federal e Territórios. [Acesso em 1ํ nov 2015]. Disponível em: http://www.tjdft.jus.br/

19 Minayo, MCS. O Desafio do Conhecimento. Pesquisa Qualitativa em Saúde. 8ª ed. São Paulo: HUCITEC; 2007.

20 Brasil. Lei Federal $n^{\circ} 8.080$ de 19 de setembro de 1990. Dispõe sobre as condições para a promoção, proteção e recuperação da saúde, a organização e o funcionamento dos serviços correspondentes e dá outras providências. [Acesso em 8 nov 2015]. Disponível em: http://www.planalto.gov.br/ccivil_03/Leis/L8080.htm

21 Lei Federal $n^{\circ} 12.401$ de 28 de abril de 2011. Altera a Lei no 8.080, de 19 de setembro de 1990, para dispor sobre a assistência terapêutica e a incorporação de tecnologia em saúde no âmbito do Sistema Único de Saúde - SUS. [Acesso em 8 nov 2015]. Disponível em: http://www.planalto.gov.br/ccivil_03/_Ato20112014/2011/Lei/L12401.htm

22 Distrito Federal. Lei Distrital no 60 de 20 de dezembro de 2011. [Acesso em 8 nov 2015]. Disponível em: http://www2.senado.leg.br/bdsf/item/id/70442

23 Silva MMF. Da racionalidade das decisões judiciais nas demandas de fornecimento gratuito de medicamentos. In: Delduque MC; Alves SMC; Netto ND, organizadores. Direito Sanitário em Perspectiva. Brasília-DF; 2015. p. 608-626.

\section{Como citar este artigo:}

Mendes JG, Santos AO. Análise dos acórdãos proferidos pelo TJDFT sobre medicamentos sem registro na Anvisa, entre 2013-2015: o debate da autorização judicial e a política de saúde. Revista Cadernos IberoAmericanos de Direito Sanitário. 2016 dez., 5 supl. 1:8-25. 